\title{
El papel de la escuela en el desplazamiento y en la conservación de la lengua malecu ${ }^{1}$
}

\section{The role of the education system in the displacement and in the conservation of the malecu language}

\author{
Carlos Sánchez Avendaño \\ Profesor Escuela de Filología, Lingüistica y Literatura, Facultad de Letras \\ Universidad de Costa Rica \\ San José, Costa Rica \\ tocumarama@yahoo.es
}

Recibido: 18-X-2011 • Aceptado: 05-XII-2012 • Corregido: 17-VI-2012

\begin{abstract}
Resumen: En el presente artículo se analiza el papel que ha cumplido la escuela en el proceso de desplazamiento de la lengua malecu (hablada en Guatuso, Costa Rica) como agente que ha promocionado la hispanización lingüística. Asimismo, se explica por qué la incorporación de este idioma como asignatura en el currículo escolar ha tenido poco impacto en su conservación y revitalización.
\end{abstract}

Palabras clave: Malecu, desplazamiento de lenguas, enseñanza de lenguas, revitalización lingüistica.

\begin{abstract}
This article analyzes the role that the Costa Rican education system has played in the process of displacement of the Malecu language (spoken in Guatuso, Costa Rica) as an agent which has promoted linguistic hispanization. Besides, it explains why the incorporation of this language as a subject in the curriculum has had little impact on its conservation and revitalization.
\end{abstract}

Keywords: Malecu, language displacement, language teaching, language revitalization

\section{Introducción}

El pueblo malecu (también denominado "guatuso" en varias publicaciones) es uno de los nueve grupos amerindios asentados en el territorio de Costa Rica en la actualidad. La mayoría de los malecus habitan en el cantón de Guatuso, provincia de Alajuela, en tres comunidades que reciben el nombre de "palenques": Margarita, Tonjibe y El Sol.

Una vez que la población hispana se constituyó en el grupo dominante en la región de Guatuso, alrededor de las décadas de 1970 y 1980, los malecus entraron en un proceso de contacto intenso con el español y con la cultura hispana. Además, su sistema de vida tradicional se ha visto modificado por la destrucción casi total de los bosques y la incorporación 
de tecnologías y valores del grupo hispano. No obstante, se han conservado hasta el presente componentes de su cultura ancestral, como la lengua, el arte verbal y la dieta tradicional, aunque su presencia en la vida cotidiana de los malecus es cada vez menor.

En particular, el malécu lhaíca, la lengua vernácula de los malecus, entró en un proceso de desplazamiento hace unas cuatro décadas. Esta situación de declive del idioma autóctono constituye un tema de discusión recurrente entre los malecus, sobre todo cuando se externan las preocupaciones sobre la continuidad histórica del pueblo malecu y la construcción de la identidad étnica (Sánchez, 2011).

En el presente artículo examinaremos dos temas que sobresalen en el discurso de los malecus con respecto a las causas de la pérdida de su lengua vernácula: la incidencia de la escuela en el proceso de declinación de esta y el impacto en su mantenimiento y revitalización desde que el idioma fue incluido como asignatura en el currículo escolar en el territorio indígena Guatuso.

\section{Datos en los que se basa el presente estudio}

El presente trabajo se basa en información de naturaleza discursiva recogida mediante grupos de discusión (o grupos focales) y entrevistas cualitativas en las que participaron 68 individuos malecus de diversos grupos etarios y de los tres palenques, así como en datos de observación directa recogidos durante un año de visitas periódicas a las comunidades.

Es necesario recalcar que en los grupos focales y en las entrevistas se obtiene un discurso que muestra las preocupaciones y creencias de los individuos acerca de un tema particular, por lo que se recoge más información que con las encuestas (Bader y Rossi, 2002; Krueger y Case, 2000), las 
cuales parten de hipótesis y elementos preseleccionados que no permiten que la persona conteste más de lo que se proporciona como opción (Russi, 1998). En este sentido, en una investigación en la que resulte más importante establecer las causas y el significado que le otorgan a un fenómeno las propias personas afectadas o involucradas, en lugar de realizar una descripción estadística, los grupos focales constituyen una excelente opción (Krueger y Casey, 2000; Morgan, 1997).

En la tabla 1, se presenta una breve descripción de las variables del grupo o el entrevistado al que corresponde cada uno de los códigos con los que identificamos la procedencia de la información:

Tabla 1

Códigos y caracterización de cada grupo de discusión o entrevistado

\begin{tabular}{|c|c|}
\hline Código & Características del grupo o del entrevistado \\
\hline $\mathrm{F} 1$ & $\begin{array}{l}\text { Grupo de discusión familiar de Margarita con una amiga muy cercana de El Sol. } 7 \text { parti- } \\
\text { cipantes de los tres grupos generacionales, con edades comprendidas entre los } 22 \text { y los } 61 \\
\text { años. } 5 \text { mujeres y } 2 \text { hombres. }\end{array}$ \\
\hline \multicolumn{2}{|l|}{$\mathrm{F} 2$} \\
\hline MG1a & $\begin{array}{l}\text { Grupo de discusión de jóvenes de Margarita. } 5 \text { participantes con edades comprendidas entre } \\
\text { los } 13 \text { y los } 17 \text { años. } 2 \text { hombres y } 3 \text { mujeres. }\end{array}$ \\
\hline MG1b & $\begin{array}{l}\text { Grupo de discusión de jóvenes de Margarita. } 4 \text { participantes con edades comprendidas entre } \\
\text { los } 13 \text { y los } 21 \text { años. Todos hombres. }\end{array}$ \\
\hline MG2 & $\begin{array}{l}\text { Grupo de discusión de adultos de Margarita. } 6 \text { participantes con edades comprendidas entre } \\
\text { los } 32 \text { y los } 40 \text { años. } 4 \text { mujeres y } 2 \text { hombres. }\end{array}$ \\
\hline MG3a & $\begin{array}{l}\text { Entrevista grupal a adultos mayores de Margarita. } 3 \text { participantes con edades comprendi- } \\
\text { das entre los } 55 \text { y los } 74 \text { años. } 2 \text { hombres y } 1 \text { mujer. }\end{array}$ \\
\hline SG1 & $\begin{array}{l}\text { Grupo de discusión de jóvenes de El Sol. } 5 \text { participantes con edades comprendidas entre los } \\
17 \text { y los } 30 \text { años. } 4 \text { mujeres y } 1 \text { hombre. }\end{array}$ \\
\hline $\mathrm{SG} 2$ & $\begin{array}{l}\text { Grupo de discusión de adultos de El Sol. } 4 \text { participantes con edades comprendidas entre los } \\
33 \text { y los } 36 \text { años. } 3 \text { mujeres y } 1 \text { hombre. }\end{array}$ \\
\hline $\mathrm{TN}$ & $\begin{array}{l}\text { Grupo de discusión de niños de Tonjibe. } 6 \text { participantes con edades comprendidas entre los } \\
9 \text { y los } 13 \text { años. } 4 \text { mujeres y } 2 \text { hombres. }\end{array}$ \\
\hline TG1a & $\begin{array}{l}\text { Grupo de discusión de jóvenes de Tonjibe. } 3 \text { participantes con edades comprendidas entre } \\
\text { los } 19 \text { y los } 24 \text { años. Todas mujeres. }\end{array}$ \\
\hline TG1b & $\begin{array}{l}\text { Grupo de discusión de jóvenes de Tonjibe. } 8 \text { participantes con edades comprendidas entre } \\
\text { los } 14 \text { y los } 26 \text { años. } 5 \text { mujeres y } 3 \text { hombres. }\end{array}$ \\
\hline TG2 & $\begin{array}{l}\text { Grupo de discusión de adultos de Tonjibe. } 6 \text { participantes con edades comprendidas entre } \\
\text { los } 33 \text { y los } 46 \text { años. } 5 \text { mujeres y } 1 \text { hombre. }\end{array}$ \\
\hline MG1c & Hombre de 29 años, procedente de Margarita. \\
\hline MG3b & Hombre de 70 años, procedente de Margarita. \\
\hline SG3a & Mujer de 57 años, procedente de El Sol. \\
\hline SG3b & Mujer de 54 años, procedente de El Sol. \\
\hline TG3a & Mujer de 61 años, procedente de Tonjibe. \\
\hline TG3b & Mujer de 58 años, procedente de Tonjibe. \\
\hline M1 & Maestro, procedente de Tonjibe. \\
\hline M2 & Maestro, procedente de Margarita. \\
\hline
\end{tabular}


Los fragmentos discursivos que se consignan deben interpretarse como ejemplos de las tendencias generales que se hallan en el corpus, sea que estas tendencias estén presentes en todos los grupos, en solo los grupos determinados por cada variable (generación y palenque) o en algún grupo en particular ${ }^{2}$.

\section{El papel de la escuela en el desplazamiento de la lengua malecu}

Aunque el pueblo malecu pudo mantener su "condición de refugio" (Bozzoli, 1969) y una relativa autonomía frente al Estado costarricense hasta por lo menos la primera mitad del siglo XX (Castillo, 2004; Constenla, 1988), ya a partir de 1928 las autoridades costarricenses impusieron la obligación de que los niños malecus asistieran a la escuela de Guatuso, sin importar que para ello tuvieran que caminar varios kilómetros a través del bosque y exponerse al peligro de encontrarse con animales salvajes, pues, de no asistir, los padres se arriesgaban a castigos de cárcel y a ser encerrados en fosos (Porras, 1959).

Aún así, los malecus continuaron viviendo en una situación de relativo aislamiento en una región con poca población de origen hispánico y rodeada de selvas. Por este motivo, de acuerdo con lo informado por Porras (1959), en la década de 1950, todavía los malecus practicaban en su totalidad la religión tradicional, habitaban en las casas al estilo autóctono, mantenían sus hábitos alimenticios y hablaban con fluidez la lengua vernácula (incluso se encontraban individuos monolingües en malecu, especialmente niños pequeños).

El cambio de esta situación se producirá en gran medida con la apertura de la escuela en Margarita en 1950 y en Tonjibe en 1965 (Castillo, 2004; Porras, 1959), dado que, con la plena incorporación de los niños al sistema educativo hispanocostarricense, de raíces occidentales, los malecus fueron introducidos en un modelo de pensamiento completamente distinto al de sus ancestros, en el cual se les enseña a razonar de acuerdo con la visión de mundo del grupo de cultura hispánica y se les instruye a identificarse con la historia oficial de Costa Rica y el "ser" costarricense. De hecho, hasta que se implementó la nueva política educativa del Ministerio de Educación Pública en la década de 1990, la educación en los palenques parece haber ignorado la especificidad histórica y cultural del pueblo malecu (Ugalde, 1973).

Esta labor aculturadora de la escuela se revela perfectamente en la defensa que de ella lleva a cabo Porras (1959) a mediados del siglo pasado, quien sostiene que los métodos represivos usados contra los padres que se negaban a enviar a sus hijos a la escuela de Guatuso se justificaban por los "halagüeños" resultados y porque la instrucción bien podía concebirse como "el paso más decisivo del indio hacia nosotros" (Porras, 1959, p.50). Así, para este filólogo, la escuela cumplió un papel crucial en llevar a los malecus hacia la "cultura", forma en la que ideológicamente se representa la aculturación hispanizante u occidentalizante de los pueblos amerindios.

A pesar de ello, en cuanto al idioma vernáculo, Porras indica que los niños de Tonjibe y de Margarita asistían a la escuela de Margarita desde 1950 y allí aprendían a escribir el malecu con los signos latinos, con adaptaciones para los sonidos "especiales", de modo que se puede interpretar que al menos se intentaba incorporar de modo parcial la enseñanza de la lecto-escritura por medio de la lengua ancestral.

Además, curiosamente, al menos en lo que respecta al primer maestro, si bien es claro que se produjo adoctrinamiento ideológico e intentos de trasladar los valores de la cultura hispana a la malecu, no se percibe una actitud negativa hacia la vida tradicional malecu en el pensamiento de Reinaldo Ballestero (1952), ni en las pocas palabras que dejó escritas ni según el recuerdo que de él conservan los ancianos malecus. 
De acuerdo con lo que relatan algunos de ellos, Ballestero llegó a aprender y manejar con bastante fluidez la lengua malecu, participaba en las festividades comunitarias y hasta les ayudaba a sus amigos a llevarles serenata a las mujeres pretendidas por estos. En el relato que publicó en 1952, Ballestero se muestra respetuoso y compenetrado con la comunidad e incluso parece esforzarse por entender la forma de comportarse de los malecus y rechazar estereotipos infundados acerca de ellos:

Es un error eso de que el indio guatuso es muy vagabundo; a todos les gusta tener su yucal; siembran caña de azúcar, arroz, maíz, frijoles, cacao y café y si siembran poco lo hacen porque es sólo para el consumo personal, pero estoy seguro que cuando se mejoren sus mercados, intensificarán sus cultivos, pues les encanta sentirse dueños de unos cuantos colones (...).

$\mathrm{Al}$ principio de mi llegada se portaron un poco huraños, porque por razones que me reservo, hubo blancos que hicieron lo posible por estorbar la labor que el Ministerio se proponía realizar en aquella zona. Habían dicho a los indios que yo llevaba instrucciones de quebrar las tinajas en que fabrican la chicha y, además, de cambiar en todo sus costumbres. Como es de suponer, estaban indispuestos conmigo, y algunos llegaron a decirme que no querían convivir con blancos porque nosotros no los queríamos y sí sólo buscábamos como hacerles daño. Otro se vino haciéndome compañía en el trayecto de Los Palenques a San Rafael de Guatuso y en el camino me preguntó si era cierto que yo pensaba destruir sus tinajas; me rogó no lo hiciera, pues a las indias les costaba mucho fabricarlas ya que tenían que acarrear la arcilla desde muy lejos; que la quemada era tarea costosísima y que a ellos les gustaba tanto beber chicha que si se les prohibía serían capaces de morir (...).Con tal noticia, todos estaban afligidos. Al contestarle yo que no había pensado causarles semejante daño y que, por el contrario, les prometía ayudarles a hacerlas más grandes ya que a mí también me gustaba beberla, corrió a dar la gran noticia a sus hermanos, lo que celebraron con una de sus tradicionales fiestas. Cuando volví, como era de esperar, me recibieron con manifestaciones de contento y con un guacal de chicha... (Ballestero, 1952, p. 156)

Porras (1959), quien coincidió con Ballestero en los palenques durante su trabajo de campo, corrobora lo informado por los ancianos y, en gran medida, confirma la actitud que Ballestero afirma haber asumido con respecto a la cultura tradicional malecu cuando apunta que este "después de cinco o seis años de mutua convivencia con los indios, conoce mejor que nadie los secretos de la lengua y costumbres del nativo" (Porras, 1959, p. 214).

Definitivamente, la posición de Ballestero llama la atención por ser contraria a la ideología dominante acerca de esta etnia en la época en la que fungió como maestro en los palenques. Con toda seguridad su presencia ayudó a que la labor escolar no tuviera un impacto tan negativo sobre la conservación del idioma vernáculo como sí ocurrió con otras lenguas indocostarricenses. Tan atípico resulta su pensamiento que es indispensable subrayar que, de modo opuesto a lo relatado, la historia del contacto entre el pueblo malecu y la sociedad de cultura hispánica está plagada de valoraciones etnocentristas de parte de la segunda hacia el primero (Sánchez, 2011).

En concordancia con lo expuesto, de acuerdo con lo informado por los participantes, al parecer no se produjo en su caso una represión sistemática contra su idioma vernáculo, una prohibición expresa de parte de los maestros de hablarlo o un castigo (físico o verbal) hacia quienes hubieran sido encontrados conversando en la lengua autóctona en la escuela, ni siquiera hace unos sesenta años, durante la niñez de los adultos mayores del presente (F1, F2, MG2, MG3a, SG3a, TG2, TG3a, TG3b). De hecho, solamente una joven de Margarita (F1) declaró haber escuchado contar a su tía cómo a ella el maestro le había prohibido hablar malecu.

Según la información recabada por Ramírez, Jaén, Mejía y Mojica (1996), algunos maestros castigaban a los niños que escuchaban hablando en malecu. Sin embargo, los ancianos a los que entrevistamos negaron haber pasado por una experiencia semejante. Esto puede deberse a que quizás el castigo se aplicaba en la escuela fuera de los palenques o a que la 
represión tal vez fue más bien esporádica. De esta manera, si nos basamos en los testimonios de los ancianos y personas mayores, el papel desempeñado por la escuela en el territorio malecu contrastaría enormemente con el cumplido en otras comunidades indocostarricenses, según lo informado por personas de otros grupos.

En Costa Rica ${ }^{3}$, los testimonios acerca de la prohibición de que se emplearan las lenguas indígenas se repiten en la información proporcionada por bribris (Palmer, Sánchez y Mayorga, 1992; Wilson, 1996), borucas (M. A. Quesada, 1995a, 1995b; J. D. Quesada, 2000, 2001/2002) y térrabas (Portilla, 1986). En el caso de los bribris, Wilson (1996, p. 73) alude al testimonio de uno de sus informantes, quien le contó que "el primer día que había asistido a la escuela, el maestro (quien era blanco y no hablaba una sola palabra de bribri) había dicho que les iba a obligar a dejar de hablar su dialecto bárbaro como primera medida para civilizarlos".

En el caso de los borucas, tras la construcción de escuelas en su territorio, los maestros no indígenas prohibían el uso de la lengua boruca tanto dentro como fuera de las aulas e incluso castigaban físicamente a los niños que no siguieran este lineamiento. A modo de ejemplo, J.D. Quesada (2000) cuenta que dos adultos borucas le mostraron cicatrices en sus cabezas, marcas de golpes propinados por maestros con el lomo de unos libros, como castigo por hablar el idioma autóctono.

Por este motivo, según J.D. Quesada (2001/2002), la escuela se convirtió en el factor desencadenante del proceso de rechazo hacia la lengua boruca, pues, antes de que se impusiera el sistema educativo hispanocostarricense en las comunidades indígenas, la represión no había sido sistemática. Desde su perspectiva, el castigo por hablar la lengua autóctona provocó que las personas cambiaran en la medida de lo posible al español y que el boruca se viera relegado cada día más al ámbito familiar, tras lo cual se empezó a romper la transmisión intergeneracional del idioma e inició su acelerado proceso de desplazamiento, el cual no ha podido ser revertido por los programas de revitalización lingüística actuales promovidos por el mismo sistema educativo oficial.

M.A. Quesada (1995a, 1995b) cuenta una historia similar de represión y castigo por parte de la escuela, que coadyuvó hasta mediados del siglo XX a que los padres les prohibieran a sus hijos (los actuales ancianos de la etnia) hablar boruca, por lo cual en la actualidad existen adultos que conocen bien el idioma pero que no se atreven a expresarse en él. Finalmente, Portilla (1986) también aduce que la represión instaurada por los maestros foráneos estaba presente en la memoria de los últimos hablantes de térraba con los que tuvo contacto y que estos la consideraban una de las razones cruciales de que se hubiera producido el abandono de su idioma vernáculo.

Como se puede apreciar, las figuras que llevaban a cabo la represión eran principalmente los maestros, encargados por el sistema educativo oficial de legitimar los valores de la cultura hispánica dominante y de extender el empleo del español, por ser esta la mejor forma de salir del "atraso cultural" y tener acceso a los beneficios de que gozaban los hispanos, de acuerdo con la ideología de la superioridad lingüística y cultural típica de los grupos hegemónicos (Wilson, 1996). Todavía hace dos décadas, esta represión continuaba siendo una preocupación para los representantes indígenas consultados con respecto al contenido que debía incluirse en una encuesta nacional sobre la percepción acerca de los grupos indocostarricenses:

Hay un elemento importante de citar: la preocupación manifiesta en torno al poder hablar en sus propias lenguas se deriva de situaciones vividas en su infancia, donde los maestros les pegaban si lo hacían bajo el pretexto de que "se están burlando de mí". (López, 1994, p. 110)

Es claro, entonces, por qué algunos lingüistas (Hagège, 2002; Skutnabb-Kangas, 
2000) insisten en el papel preponderante de la escuela como agente que promueve la aculturación y el monolingüismo en la lengua del grupo dominante y enfatizan el papel represivo de los maestros, quienes históricamente han prohibido y castigado el uso de los idiomas autóctonos por parte de los niños, provocando con ello una actitud de vergüenza y rechazo hacia la cultura de los ancestros.

Como ya adelantamos, en el caso de los malecus no parece haber tenido lugar la represión sistemática, pero de todos modos habría actuado la "persuasión ideológica" (van Dijk, 2000), mecanismo que promueve determinadas representaciones sociales beneficiosas para los intereses de los grupos de poder. Por ejemplo, destaca el papel de la escuela en la implantación de ideologías que incentivan una adscripción identitaria nacional costarricense en detrimento de la identidad diferenciada malecu.

En el discurso de los malecus, la escuela aparece explícitamente como una causa del desplazamiento del idioma malecu ligada a la necesidad de aprender español para poder desenvolverse en la clase y cumplir con las demandas del sistema educativo formal. Dado que los malecus fueron obligados a enviar a sus hijos a la escuela y debido a que la instrucción se llevaba a cabo en español y que no se enseñaba este idioma con una metodología adecuada para su aprendizaje como segunda lengua, no es de extrañar que los adultos recuerden su etapa escolar como un período de mucha frustración y dificultad.

Inevitablemente, debió de haber operado desde épocas tempranas la asociación del español con el éxito académico (y la oportunidad de tener acceso a determinados conocimientos) y del monolingüismo en malecu con el fracaso escolar. Por ello, la implantación del sistema educativo costarricense hispanizante sin duda constituye uno de los ejes centrales del proceso de desplazamiento del idioma vernáculo, al privilegiar el uso del español como lengua de instrucción.
Solo teniendo en mente lo anterior se puede comprender por qué, aunque no se produjo represión, la apertura de las escuelas en los palenques y la inserción de los malecus en el sistema educativo formal costarricense aparecen, de uno u otro modo, vinculadas a la declinación de su lengua vernácula (F1, MG2, SG1, SG3a, TG1b, TG2, TG3a, TG3b). Eso sí, su relevancia como factor que ha incidido en este declive es más clara en el discurso de los adultos que en el de los jóvenes, debido a que la mayoría de los muchachos más bien tienden a asociar la escuela con clases formales de lengua malecu. Por el contrario, los adultos sí recuerdan su escolarización como un proceso en el que el español adquiría cada vez mayor importancia mientras el malecu se relegaba a la comunicación en el hogar.

Así, en general, la discusión en torno al papel de la escuela suele subrayar la necesidad de haber aprendido español para entender las explicaciones de los maestros y poder llevar a cabo las tareas y exámenes. También se destaca la mayor práctica del español a causa de la escuela. En otras palabras, el papel de la escuela en el desplazamiento del malecu se plantea con la siguiente cadena de factores: apertura de la escuela $\rightarrow$ necesidad de aprender español para desenvolverse en ella $\rightarrow$ mayor uso y práctica del español $\rightarrow$ abandono progresivo del malecu. En el fondo, se reconoce que la castellanización ha conllevado al desplazamiento paulatino de la lengua vernácula.

Véase lo que al respecto explica un adulto mayor de Margarita (F1), quien responsabiliza a la escuela y a la instrucción en español por la pérdida de la cultura malecu y el idioma autóctono. En particular, nótese cómo el problema surge porque el maestro era hispano (chiúti) y, según se infiere, impartía sus clases en español:

A: (..) cuando yo fui a la escuela / no era un indígena que / que me estaba dando clase

I: ¿era un chiúti?

A: era un chiúti / entonces de ahí / viene mi interés / por hablar / el español / y entender / lo que la escuela me / me estaban enseñando / mis padres 
no sabían / no había ningún maestro / entonces lamentablemente es ahí / donde entró la raíz / de que nuestra cultura / fuera desvaneciéndose / fuera eh: / perdiendo (...)

A esta explicación de la incidencia de la escuela, particularmente en cuanto a las dificultades que experimentaron quienes no hablaban español al inicio de las clases por ser esta la lengua de instrucción, se suma el que en el pasado el malécu lhaíca estuviera ausente del aula. Así lo expone la siguiente mujer adulta de El Sol (F1):

(..) yo hablaba puro puro malecu / porque eso es lo que mi mamá me enseñó / y cuando fui a la escuela / cero español / tuve problemas en la escuela / porque no podía hablar español / y tuve mucha complicación / pero diay a raíz de que / tenía que ahí aunque sea a la fuerza ¿verdad? / aprender en la escuela / y ahí donde ya fue / ya fui hablando español y español / y diay sí vea lo que ha pasado / ya se fue el malecu / ya es poco lo que uno habla el malecu / entonces sí / a través de lo que es la escuela / o si fuera en aquellos tiempos / como ahora que que / actual este / están dando clase malecu / cultura / tal vez si hubiera sido que que sí se hubiera rescatado bastante / pero diay ya lo pasaron tarde / meter este / malecus este / eh / cultura y malecu en la escuela / porque cuando yo en aquellos tiempos / diay imagínese que ni existía eso / clase malecu ni nada por el estilo / netamente solo español y español y español.

Apréciese la valoración explícita sobre el papel de la escuela: la participante tuvo que aprender español "a la fuerza" para superar los problemas con los que se encontró al iniciar su escolarización, puesto que las clases se llevaban a cabo únicamente en este idioma, mientras que el malecu ni siquiera se consideraba dentro del currículo. Resulta interesante observar cómo el relato se abre y se cierra con una indicación de que el espacio comunicativo estaba ocupado solo por una lengua: durante su infancia en el hogar la situación lingüística se caracterizaba por ser "puro puro malecu", mientras que la situación lingüística en la escuela era de "netamente solo español y español y español”. De ello se desprende que el bilingüismo ha constituido la transición histórica entre el monolingüismo en malecu y el monolingüismo en español.
En diversos pueblos amerindios, los padres cesan la transmisión de la lengua vernácula y hasta se oponen a la inclusión de esta como materia de estudio escolar, dado que están convencidos de que constituye un obstáculo en el proceso de aprendizaje del español, el idioma que asocian con mejores oportunidades de empleo y bienestar socioeconómico (Palacios, 2004). Así, por ejemplo, la preocupación de los padres kaqchikel (Garzon, Brown, Richards y Ajpub', 1998), k'iche' (Lewis, 2001) o quechuas (Howard, 2007) reside en que los niños aprendan español, con la esperanza de que aumenten sus posibilidades de ascenso social y disminuyan las dificultades para tener éxito en la escuela.

En su experiencia, estos adultos se vieron forzados a escolarizarse según los parámetros de un sistema educativo occidental totalmente irrespetuoso de su especificidad cultural y en un idioma desconocido para ellos, el cual tuvieron que aprender a la fuerza sin métodos sistemáticos de enseñanza de segundas lenguas, con el fin no solo de dominar el sistema idiomático nuevo, sino sobre todo de ser capaces de comprender los temas que se enseñaban (por lo demás, completamente ajenos a su cultura autóctona, pues el cometido básico ha sido la aculturación y de ahí que se enseñe historia, matemáticas, ciencias, etc. desde la perspectiva del grupo dominante y su sistema ideológico).

Esta experiencia escolar, sin duda traumática (como se colige de los testimonios de individuos de diversos pueblos), cimentó la creencia de que las dificultades supuestamente cognitivas y lingüísticas eran provocadas por la lengua vernácula, soslayando con ello el hecho de que el problema de fondo era la imposición forzada y "de golpe" de un sistema cultural distinto en lo concerniente a visión de mundo, costumbres, educación y conocimientos, mediante la lengua del grupo dominante, la cual posiblemente se enseñaba como si fuera la lengua materna de los niños indoamericanos (al menos así parece haber ocurrido en Costa Rica). 
Es probable, asimismo, que la consideración de la lengua vernácula como un obstáculo para el aprendizaje de la lengua del grupo dominante no solo haya surgido de las experiencias de fracaso escolar de los ancianos y adultos, sino sobre todo como apropiación y reproducción de una convicción de los maestros, quienes habrían hecho creer a los padres y niños indígenas que el escaso éxito en la escuela se debía a la interferencia del idioma ancestral (y, sin duda, a su condición de indígenas) ${ }^{4}$.

Ciertamente, en este contexto, es comprensible que el problema sea planteado, desde la perspectiva de los padres, como de índole lingüística, atribuyéndole a la adquisición y dominio de la lengua vernácula la responsabilidad del "mal" español hablado por ellos y las concomitantes dificultades para poder desempeñarse con éxito en la escuela. En el caso de los malecus, de los datos recogidos se colige que el cese de la transmisión de la lengua vernácula no se debió a la creencia de los mayores de que esta interfería con el aprendizaje o dominio del español, sino que la preocupación principal fue la necesidad de adquirir la lengua en la que se llevaba a cabo la educación en la escuela, para con ello evitar el fracaso académico.

Al respecto, el siguiente relato de una mujer tonjibeña (TG2) ilustra a la perfección cómo el desconocimiento del español, la lengua de instrucción impuesta en las escuelas, constituyó el principal obstáculo en el éxito académico de muchos niños:

(...) mi papá todo el tiempo me hablaba en malecu / y y venía yo aprendiendo así / o sea en malecu / diay a mí me decían que el abecedario aquí / abecedario allá / ni la a ni la e ni la i ni la u la podía pronunciar / yo no podía pronunciar \{el español\} / hasta que: / bueno / en el kínder más o menos me aprendí un poco / más o menos / pero no mucho / y después este / diay / tuve que quedarme varias veces en primer grado / y yo creo que dos veces en sexto grado / porque no no / o sea / no es porque no sabía lo que: / sino el problema era que el español / ese era el problema / el español.
Todavía en el presente, algunos jóvenes (F1, TG1b) atribuyen la interrupción de su adquisición del malecu al inicio de sus estudios de secundaria, debido a que este no se enseña, sino que más bien se imparten clases de otros idiomas y ellos tienen que adaptarse más a los hispanos. Así, si bien la situación que vivieron los adultos en la escuela ha cambiado parcialmente (en realidad la diferencia estriba en la incorporación de clases de malecu, puesto que las demás materias han continuado impartiéndose solo en español), en la secundaria sigue siendo la misma: el malécu lhaíca está completamente ausente.

En el fondo, esta necesidad de adaptación al contexto colegial repite la experiencia por la que pasaron los adultos y ancianos décadas atrás en el contexto de la primaria. Por ejemplo, algunos jóvenes de Tonjibe (TG1b) muestran conciencia con respecto al proceso de pérdida de su competencia en la lengua vernácula, desarrollada al menos parcialmente antes de entrar a la escuela, y la achacan al mayor uso del español debido a dos factores: el contacto más frecuente con los hispanohablantes y el inicio de los estudios formales. Es evidente, entonces, el papel que cumplen las instituciones de educación en el desplazamiento del malécu lhaíca al crear un ambiente en el que se privilegia el español:

A: en mi caso / cuando yo estaba en la escuela yo hablaba bastantillo / (XX) yo hablaba bastantillo / pero después que cambié de escuela a colegio / me tuve que adaptar más a los / a la gente blanca / (...) / entonces se me fue olvidando el malecu y le puse más importancia a la otra cosa / ese fue el problema B: el caso mío que: / mi mamá me me dijo que: / yo venía chiquitita hablando / me dijo que: / que ella venía diciéndome "esto se dice en malecu y esto" (XX) / y mi tía que dijo que uno va creciendo ¿verdad? / ya cuando uno está grande / ya creció / ya / totalmente se le olvidó el malecu / porque desde que / dice mi mamá que apenas entré al co- a escuela / ya este: aprendí este: / malecu / bueno español / o sea los dos juntos / pero el que practiqué más es el español / entonces ahí es donde: / me cuesta mucho hablar malecu ¿verdad? (...) 


\section{El papel actual de la escuela en la enseñanza de la lengua malecu}

Según lo descrito, el común denominador de las políticas lingüísticas en Costa Rica en relación con las lenguas minoritarias fue, hasta avanzada la segunda mitad del siglo XX, la aculturación de las comunidades y la prohibición de que se usara la lengua vernácula en la escuela. M.A. Quesada (1999/2000) señala en este sentido que, durante el siglo XIX y gran parte del XX, el sistema educativo costarricense se caracterizó por el centralismo y por la castellanización como la política lingüística oficial, lo cual se aparejó con la represión (corporal, pero también cultural y psicológica) por emplear las lenguas indígenas.

El cambio en la oficialidad parece comenzar con el Decreto Presidencial n¹ de 1950, que establece la protección y el desarrollo del nivel cultural de vida y la conservación de las poblaciones indígenas de Costa Rica. Años después, en 1985, se publica el Decreto n¹6619 del Ministerio de Educación Pública, el cual establece un modelo curricular bilingüe y bicultural. El plan de formación de maestros que siguió a este decreto declara la necesidad de enseñar y reafirmar el uso de dos lenguas y de varias culturas, además del cuidado que debía tenerse para que la cultura y el idioma del grupo mayoritario no aparecieran como dominantes (M.A. Quesada, 1999/2000, 2008).

Luego, el Decreto Ejecutivo n¹8967 de 1989 estableció que el estatus de las lenguas vernáculas sería el de lenguas locales y que estas serían consideradas parte del patrimonio cultural de la nación. Asimismo, declaró el apoyo del Estado en la conservación y promoción de las lenguas autóctonas y encomendó su estudio científico, la difusión de las literaturas tradicionales, la creación de materiales para la alfabetización y la implementación de la educación bilingüe (Rojas, 1997/1998; M.A. Quesada, 1999/2000).
El Decreto Ejecutivo n²2072 de 1993 del Ministerio de Educación plantea como metas de la educación en los territorios indígenas la conservación de los idiomas y la formulación de estrategias para rescatar las lenguas en proceso de muerte (Rojas, 1997/1998; M.A. Quesada, 1999/2000). Finalmente, el Decreto Ejecutivo n²3489 de 1994 crea el Departamento de Educación Indígena y le asigna las funciones de contextualizar el currículo escolar a las características y requerimientos de la población amerindia, y de promover la educación bilingüe y pluricultural (Rojas, 1997/1998).

Rojas (2002) señala que en 1997 el Consejo Superior de Educación, por medio de la Resolución 34-97, incluyó dos asignaturas en el currículo de las escuelas indígenas: la de idioma indígena (con tres lecciones semanales) y la de cultura indígena (con dos lecciones semanales). Los objetivos del Programa de Enseñanza de las Lenguas Indígenas se resumen en revitalizar y difundir tales idiomas por medio de la educación de niños y jóvenes, desarrollar las habilidades expresivas (tanto orales como escritas) en las lenguas vernáculas, incentivar el aprecio por las muestras de literatura tradicional, promover la educación bilingüe, y facilitar la transición hacia el español en las comunidades cuya lengua materna sea la indígena.

En teoría, de acuerdo con esta autora, la finalidad principal consiste en fortalecer las culturas amerindias y la identidad étnica de las personas, por medio del incentivo del conocimiento y la revaloración de las prácticas tradicionales, la historia, los conocimientos ancestrales y la relación con la naturaleza. No obstante, con excepción del boruca para primaria y del cabécar y el bribri para secundaria, se trabaja con programas provisionales. Asimismo, se crearon los puestos de maestro de lengua indígena y maestro de cultura indígena, quienes deben ser hablantes nativos fluidos de los respectivos idiomas de las comunidades y formados en las costumbres tradicionales de cada pueblo. En el caso 
del pueblo malecu, se cuenta en la actualidad con dos maestros itinerantes (uno de lengua y otro de cultura) que atienden la escuela de Margarita y la de Tonjibe, mientras que los niños de El Sol aún no reciben dicho servicio.

Entre los obstáculos relacionados con el éxito de estas medidas educativas, Rojas (2002) menciona la inexperiencia administrativa y "mental" para lidiar con la diversidad cultural, la falta de planificación política y educativa, problemas en la coordinación y delimitación de las funciones de cada una de las organizaciones e instancias gubernamentales involucradas (duplicación de esfuerzos, contradicción en la toma de decisiones, divisiones internas en las comunidades), escasez de recursos para la producción de material educativo en sus diversas fases, y discriminación hacia los maestros de lenguas indígenas por parte de los docentes regulares y autoridades educativas por no contar estos con formación universitaria acreditada para transmitir los saberes tradicionales.

A tales inconvenientes, Vásquez (2008, p.62) agrega que la iniciativa de incluir las lenguas indocostarricenses en el currículo escolar destaca por su carácter "estandarizado", "genérico" y "homogenizado", de manera que se han tratado con las mismas estrategias situaciones lingüísticas y culturales muy disímiles. También se aprecia escasa fundamentación técnica y científica en la enseñanza lingüística, carencia de programas didácticos adecuados para cada caso, y falta de maestros formados en pedagogía (a lo que se suma su deficiente manejo de los sistemas de escritura de las lenguas vernáculas). A pesar de todo esto, Rojas (2006) expone que las actitudes hacia la enseñanza de las lenguas indígenas en Costa Rica parecen ser positivas, tanto de parte de los padres como de los mismos alumnos indocostarricenses.

En el presente, en lo que respecta al papel de la escuela en la conservación de su lengua vernácula, los malecus frecuentemente le asignan a esta institución la responsabilidad de enseñarles el idioma ancestral a los niños, sobre todo debido a la inoperancia de los hogares en la transmisión de este y a la creencia de que las asignaturas de idioma y cultura malecus sirven para conservar y rescatar la cultura tradicional.

Aunque algunos adultos consideran que los niños sí están aprendiendo algo del idioma en la escuela (SG3a, TG1b), la mayoría son sumamente críticos con respecto al desempeño de los maestros y con los resultados obtenidos hasta el momento. Asimismo, algunos jóvenes afirman que mucho de lo que saben lo aprendieron en la escuela, total o parcialmente (F2, MG1a, MG1b, SG1, SG2), pero también hay quienes declaran que lo que saben no proviene tanto de la escuela como de sus casas (MG1a, TN).

En cualquier caso, la opinión más generalizada es que las clases no están cumpliendo con el objetivo de lograr que los niños aprendan malécu lhaíca (F1, MG1b, MG2, MG3a, TG2). Las principales quejas conciernen a la metodología (F1, MG3a), el desempeño y la actitud de los maestros (F1, MG2, MG3a, TG2), el desinterés de las jerarquías de las escuelas (MG2, MG3a), el escaso estatus de las clases de malecu en relación con las demás asignaturas (MG1b, M2) y la veracidad de lo enseñado (MG2, MG3a), referido este último aspecto a los intentos de acuñación de nuevas palabras que el maestro de lengua les enseña a los niños, sin haber sometido sus propuestas a la aprobación consensuada por las comunidades.

Más puntualmente, se insiste en que en la clase de malecu únicamente se enseñan palabras sueltas, se expone que los maestros no hablan malecu fuera de la clase, se resalta que la Dirección de la Escuela de Margarita no tiene interés por la lengua vernácula, se enfatiza que la asignatura de malecu funcionaría mejor si tuviera más lecciones y se tomara más en serio, y se asevera que los maestros no son claros en cuanto a lo que esperan de las 
tareas ni muestran una actitud receptiva para atender las dudas de los padres.

Los siguientes jóvenes de Margarita (F1) se refieren al problema de que la enseñanza escolar no brinda las herramientas para entablar una conversación en el idioma autóctono. Básicamente, entonces, aluden a un método que no prepara a los niños para el uso efectivo de la lengua y que ni siquiera los capacita para producir y comprender oraciones, sino que se limita a enseñar palabras sueltas:

A: (...) en las escuelas sí se enseña el malecu / pero si se enseñara al cien por ciento puede la probabilidad de que tal vez se rescate / que el malecu tienda a durar más / pero el malecu ya / se enseñan unas que otras palabras / nada más / no se enseña así como que si fuera todo fluido / como el inglés / que va usted a las clases y que todo lo tenía que hacer hablado / no / el malécu lhaíca ya son solo palabras / así

B: $\quad$ porque / de hecho usted va adonde uno de esos chiquitos que le enseñan el malécu lhaíca / ellos no te dicen una oración completa / o cinco minutos / ellos no te hablan cinco minutos malecu / para mí eso es un / un método obsoleto / como dice / ese método para mí no sirve / eh / sí le enseña algunas palabritas / algunos animalillos así / pero digamos que / que le digan / que yo vaya “imá jué capíya miunh maráma? / ¿írre orróqui irrjóye unh maráme? / ¿írre misa octenh? / ¿má jué póti malécu lhaíca uráje?” [[¿cómo están? / ¿qué están haciendo? / ¿cómo se llama su papá? / ¿usted sabe (hablar) malecu?]] / ya una conversación así ya no me lo van a responder (...)

Pese a que, en apariencia, B se refiere a la imposibilidad de construir "oraciones", en realidad no está aludiendo a que en la clase de malecu debería enseñarse gramática, sino a que los niños no pueden engarzar las palabras que aprenden de modo aislado en estructuras morfosintácticas que sirvan para comunicarse en la vida cotidiana mediante un discurso continuo, de ahí que afirme "ellos no te hablan ni cinco minutos malecu" y "una conversación así ya no me lo van a responder". En el fondo, se subraya la falta de un método que propicie el desarrollo de la competencia comunicativa y se critica la concentración de la clase de malecu en la enseñanza de palabras descontextualizadas que no se llegan a emplear nunca en construcciones con alguna función pragmática.

Por su parte, los maestros señalan que uno de sus principales problemas consiste en no contar con programas de estudio ni materiales didácticos adecuados, pero, sobre todo, achacan el relativo fracaso de la labor escolar al desinterés de los padres con respecto al aprendizaje de la lengua y la cultura tradicionales por parte de sus hijos. En el siguiente fragmento, uno de los maestros expone cuál es su visión acerca de los logros alcanzados y cómo afecta el desinterés y poca colaboración de los padres en los resultados de su labor:

(...) en Margarita y El Sol / se estaba perdiendo / cuando yo llegué en el: noven- / este / noventa y seis / yo llegué en esa escuela / a pesar que soy de la comunidad / de las tres comunidades pero / radicado yo aquí en Tonjibe / yo llegué / el primer día / y cuando saludé al grupo de niños / todos estos niños no contestaron nada en malecu / es preocupante / y: sentí triste / me senté / dije yo "voy a sentarme a llorar" / cómo realmente Margarita que está poco / a dos kilómetros de Tonjibe / se estaba yendo el idioma / sin embargo fui duro / yo le di- / le pedí un tiempo prudente al Ministerio de Educación / le digo / "en tres años / yo le voy a recuperar / una parte / de lo que quizás está perdiendo en Palenque Margarita / efectivamente / tres años más tarde / ya / logré que los chiquitos dijeran / "buenos días" en malecu / “¿cómo está?” / eh: / identificar que son el malecu / que no se avergüence de / de su propio idioma / identidad / y hoy estamos en: / este: / dos mil / diez / que en Margarita ya tengo niños que realmente habla el malecu / algunos eh: / que no son indígenas / hablando el malecu / pero el problema más grande NO está del maestro / el el problema está en la casa / el maestro indígena / el campo que me corresponde / yo lo que soy es un: simple este / facilitador / en los tres lecciones que tengo en ello por semana / entonces / simple apoyo para ello / el trabajo total de la educación del habla malecu está en los padres de familia / si ellos no lo ayuda ahí / estamos perdidos / cuando hablamos de que quién es el malecu / quién habla / todo el mundo en Margarita Tonjibe El Sol dice / "yo / soy hablante malecu” / pero: / “qué pasa con su hijo en la escuela?" / o sea que no colabora con los este: / los hijos en la escuela / entonces estamos ahí / si el papá no tiene interés / peor el niño / aunque el maestro desea que lo hable cien por ciento / pero sin embargo / yo veo que se ha logrado este / eh: / rescatar un poco del idioma que está perdiendo en Margarita / El Sol / 
En lo que respecta a la metodología, cabe resaltar que la carencia de formación de los maestros en didáctica de lenguas, la ausencia de programas de estudio y la práctica inexistencia de materiales didácticos apropiados claramente se han constituido en tres de los factores principales para que la incorporación del malecu en el currículo escolar haya tenido un reducido impacto en el aprendizaje de la lengua vernácula, al menos en lo relativo al incremento de la competencia lingüística de los niños y jóvenes.

Según lo declaran varios participantes, en la clase de lengua malecu se enseñan palabras y la construcción de algunas oraciones (F2, MG1a, MG1b, TG1a, TG1b, $\mathrm{TN}$ ), así como historias y cantos tradicionales (MG1a, SG1, TG1a), pero el aprendizaje siempre pasa por el filtro de la traducción al español. Es decir, los contenidos de aprendizaje son básicamente tres: vocabulario aislado, oraciones hechas y estudio de textos tradicionales, sin mayor sistematicidad en lo que respecta a la enseñanza de las destrezas lingüísticas y del sistema gramatical. La evaluación parece basarse también en la comprobación del aprendizaje de vocabulario y en la traducción.

A la disconformidad expresada por muchos de los participantes con respecto a que en las clases se enseñan "inventos" del maestro, palabras que en realidad "no existen” (MG1a, MG2, TG1b, TG2), lo que provoca confusión, desinterés y rechazo por la asignatura de parte de los niños, se suma otra actitud negativa: la consideración de las clases como aburridas por la monotonía del método y la repetición constante de los mismos contenidos (F2, MG1a, MG1b, TN, TG1a). Sin embargo, algunos también declaran sentir gusto e interés por la asignatura (MG1a, MG1b, TN) y, en general, se valora positivamente que la lengua vernácula se haya incorporado al currículo escolar (MG1c, SG2, SG3a).

De acuerdo con lo expuesto, no parece que la escuela esté teniendo mucho impacto en el intento de preservación y revitalización del malécu lhaíca. De hecho, nuestros datos de observación directa confirman la impresión de los participantes en cuanto a que los jóvenes se gradúan de la escuela sin haber adquirido siquiera una competencia lingüística mínima. Por lo demás, su competencia comunicativa se limita a unas cuantas rutinas de interacción (básicamente saludos, despedidas y formas para decir el nombre y para preguntar por este) y es evidente que no son capaces de entablar una conversación en malecu ni tampoco pueden leer o escribir en el idioma vernáculo.

En relación con los problemas de índole metodológica, dos aspectos más requieren de nuestra atención. Por un lado, como ya lo señalamos, no existe preparación de los maestros en didáctica de segundas lenguas, pese a que el malecu debería enseñarse en tal modalidad. Por otro, el "argumento de la epistemología interna" parece obstaculizar también la participación de especialistas externos a la comunidad. Con respecto al primer aspecto, nos parece fundamental comentar un problema mencionado por Rojas (2002), con el fin de comprender la dificultad que engloba la implementación de programas educativos encaminados a incorporar las lenguas indígenas costarricenses en los currículos oficiales:

[L]a forma de aprender y enseñar, así como las normas de interacción propias de las culturas indígenas, han sido poco estudiadas, por lo que se ha entendido que el docente de lengua indígena debe enseñar y evaluar como lo hacen los otros maestros, que la lengua indígena debe enseñarse tal y como se enseñan las lenguas modernas y que la integración de estos docentes a las escuelas debe estar regida por las normas de interacción occidentales. (Rojas, 2002, p.184)

Rojas da a entender que las clases de lengua indígena deberían basarse en los principios de enseñanza-aprendizaje tradicionales de la cultura y no seguir los parámetros de enseñanza de segundas lenguas; sin embargo, quiérase o no, la incorporación de las asignaturas de idioma vernáculo 
y cultura ancestral en los currículos escolares responde a una tradición occidental del aprendizaje, así que -en nuestra opiniónresulta normal que la lengua indígena, al ser insertada en este nuevo contexto educativo, se enseñe como cualquier otro idioma. Es decir, la didáctica de las lenguas indígenas como segundas lenguas (o primera lengua, en el caso de que todavía sean adquiridas por los niños en entornos "naturales") constituye la vía adecuada a seguir cuando se produce su inserción en el currículo de las instituciones educativas de origen occidental y, por lo tanto, los maestros indígenas deberían recibir formación en didáctica de segundas lenguas.

Ciertamente ello no implicará que se logren niveles de adquisición altos ni que se revitalice su empleo dentro de la comunicación cotidiana, pero al menos se les estará dando el mismo estatus que cualquier otro idioma que se estudie en la educación formal y se seguirán los mismos métodos modernos de didáctica de segundas lenguas. Pretender lo contrario no solo actuaría en desmedro de los intentos de planificación del estatus de tales idiomas, sino que, sobre todo, nos conduciría a una contradicción insalvable: ¿por qué queremos incorporar una asignatura de lengua indígena en el currículo escolar si lo que se pretende es que esta se enseñe y aprenda según los parámetros de adquisición informal?

Si lo que se persigue es la adquisición "natural" o "informal" (Krashen, 1981), se requeriría reactivar los mecanismos de "instrucción" tradicionales: la transmisión intergeneracional del idioma en contextos cotidianos de comunicación participativa (semejante, de cualquier manera, en todas las sociedades humanas) y la enseñanza de los textos del arte verbal de acuerdo con los criterios tradicionales (en el caso de los malecus: como patrimonio exclusivamente familiar, transmitidos a los niños durante la noche o en los descansos de la faena en el campo, y memorizados por los aprendices tras escucharlos tan solo tres veces). El principal escollo a este respecto radica en que la transmisión "natural" de la lengua y la enseñanza tradicional del arte verbal se interrumpieron desde hace años y no parece fácil revitalizarlas en las condiciones de vida actuales.

Nuestra argumentación no debe interpretarse como una defensa de lo que Sachdev y Hanlon (2000/2001) denominan la "orientación a la transmisión" en la metodología europea de enseñanza formal de idiomas frente a la enseñanza tradicional. En la orientación a la transmisión, se enfatiza el aprender "sobre" la lengua en vez de privilegiar la tradición oral, el aprendizaje informal y el uso de las lenguas en situaciones cotidianas. En el caso de los malecus, no parece producirse en la escuela tal orientación a la transmisión, pero el problema es que tampoco se sigue un programa sistemático ni planificado de enseñanza lingüística.

En lo concerniente al argumento de la epistemología interna, como lo expone Verkuyten (2006), es común la creencia de que únicamente los miembros de un mismo grupo social son capaces de comprender su situación, su historia y sus emociones, y de que, por ende, los investigadores o agentes que no pertenecen al grupo no pueden entender qué significa sufrir la discriminación o vivir en dos culturas, por ejemplo. Este argumento solo aparece de modo insinuado en dos entrevistas (MG3a, M2), pero la observación directa reveló que es relativamente habitual entre los malecus cuando estos tratan el tema de su cultura. En este caso, la proposición ideológica sería "solamente los malecus pueden entender, enseñar o aprender bien la lengua vernácula y la cultura tradicional". Por ello, el maestro de cultura aduce que los asesores del Ministerio de Educación no pueden llegar a capacitarlos sobre técnicas para enseñar lengua y cultura porque no saben hablar malecu.

El argumento de la epistemología interna es legítimo en tanto se tome c como una llamada de atención para que el investigador o agente externo a la comunidad se 
preocupe por comprender el marco conceptual y experiencial de los individuos y de los grupos con los que trabaja, pero puede convertirse en un serio obstáculo cuando se emplea como excusa para descartar la participación de "foráneos" en los proyectos o iniciativas, o para negarse a recibir asesoría experta.

En todo caso, lo más importante es que no se tiene conciencia de que la clase de idioma malecu no podrá per se incidir mucho en su conservación o revitalización. De hecho, los resultados parecen ser bastante desalentadores, a juzgar por la precaria situación de la lengua en el presente (Sánchez, 2011), a más de una década de hacer iniciado el programa de enseñanza formal en Margarita y Tonjibe. Es decir, en las condiciones de vida actuales, la escuela no logrará hacer lo que los hogares no hacen: transmitir el malécu lhaíca, crear hablantes competentes y restituir su empleo en la comunicación cotidiana intraétnica.

En este sentido, urge determinar con la comunidad cuáles son los objetivos que se desean alcanzar con la asignatura de lengua malecu $\mathrm{y}$, sobre todo, diseñar en conjunto medidas más eficaces para el mantenimiento o revitalización de su idioma ancestral.

\section{Conclusiones}

En las teorizaciones sobre la muerte de lenguas, se suelen citar las políticas lingüísticas, expresas o tácitas, como uno de los factores más importantes que promueven la reducción de la diversidad lingüística (Crystal, 2001; Hagège, 2002; Tsunoda, 2005). Sin embargo, probablemente más importante aún es la labor realizada por la escuela en la implantación y reproducción de las ideologías hegemónicas, así como en la promoción de las lenguas de los grupos dominantes en desmedro de los idiomas de los grupos minoritarios (Skutnabb-Kangas, 2000).
Por este motivo, la incidencia de la escuela no puede resumirse en su labor represiva, pues con ello estaríamos simplificando en extremo su papel y, sin duda alguna, estaríamos obviando la complejidad del entramado ideológico que subyace a su razón de existir. Si bien la represión física y psicológica del uso de las lenguas indocostarricenses, la prohibición expresa de hablarlas, ha tenido un impacto sumamente negativo en su mantenimiento, como se evidencia en los testimonios de individuos procedentes de diversos pueblos indocostarricenses, no debemos olvidar que quizás más importante aún ha sido la hispanización lingüística y cultural de los grupos con culturas y lenguas distintas a la hispánica, que ha supuesto la pérdida de la especificidad cultural e histórica de los pueblos amerindios en Costa Rica, como lo muestra el caso de los malecus.

Si bien la incorporación de las lenguas amerindias en el currículo escolar de los territorios indígenas constituye un cambio radical en la política lingüística oficial del Estado costarricense, es bastante improbable que se lleguen a alcanzar resultados positivos en cuanto a la conservación o revitalización de tales idiomas, no solo por la escasez de recursos didácticos y económicos, por la inexperiencia o las limitaciones diversas con que se enfrentan los actores involucrados o por la falta de formación de los maestros en enseñanza de segundas lenguas, sino en especial porque la escuela no puede sustituir los espacios de socialización lingüística cotidiana en los que normalmente se produce la adquisición de los idiomas vernáculos. Así lo demuestra el caso de la lengua malecu.

\section{Notas}

1 Durante el tiempo que tomó el análisis de los datos presentados en este artículo, el autor contó con una beca de la Agencia Española de Cooperación 
Internacional para el Desarrollo. Para el trabajo de campo, contó con el apoyo de la Universidad de Costa Rica. Deseo agradecerle al M.L. Henry Angulo Jiménez por corregir la traducción del resumen al inglés y a la M.L. Patricia Guillén Solano por la revisión filológica del texto.

Algunos fragmentos de ejemplo constan de más de una intervención, dado que participan dos o más hablantes, incluyendo al moderador. Cuando esto ocurre, cada intervención se introduce con una letra mayúscula de la $\mathrm{A}$ a la $\mathrm{E}$ y, en el caso del investigador, sus intervenciones se señalan con I. En los ejemplos se sigue la ortografía regular del español y la ortografía práctica del malecu (Constenla, 1998). Las claves de transcripción son las siguientes: / (pausa breve o linde entre enunciados), // (pausa prolongada), [ ] (habla simultánea en el interior de una intervención), $<$ [ ] (habla simultánea iniciada al final de la intervención del participante anterior), MAYÚSCULA (énfasis del hablante: mayor volumen de voz, pronunciación marcadamente segmentada), \{\} (comentarios del transcriptor), (XX) (fragmento ininteligible), (( )) (transcripción dudosa), (...) (fragmento de la grabación omitido), - (truncamientos de palabras), : (alargamiento de segmentos fónicos), cursiva (fragmentos en malecu), [[ ]] (traducción al español de los fragmentos en malecu), "” (fragmento de discurso directo, casi siempre en un relato conversacional), «» (fragmento de discurso directo dentro de otro discurso directo).

La situación parece ser general en todo el continente americano. Por ejemplo, en Colombia, Pachón (1997) asegura que los maestros tradicionalmente han castigado físicamente y han despreciado a los niños por hablar el páez, idioma considerado por estos como incivilizado e inservible para la enseñanza formal o para la transmisión de saberes sofisticados. Esta misma represión se documenta para los pueblos chocó (Pardo, 1997), las etnias de la Amazonía colombiana (Aguirre y Reinoso, 2006), los navajos (House, 2005), los kaqchikel (Garzon, Brown, Richards y Ajpub', 1998) y los quechuas (Howard, 2007).

4 Así se infiere del contenido de las actas de los cuatro Seminarios de las Escuelas Indígenas de 1953. Por ejemplo, en el acta del cuarto seminario, realizado en Salitre, se aprecia con facilidad que los idiomas vernáculos, y especialmente el monolingüismo infantil en ellos, se conciben en realidad como barreras para alcanzar los propósitos pedagógicos: "Don Tito Acosta nos habla sobre Metodología de la Composición en todos los grados de la Escuela Primaria. Hizo interesantes recomendaciones basadas en su larga práctica como maestro de las Escuelas Indígenas. "En el primero y segundo grados -dijo don Tito- el asunto es más delicado tratándose de alumnos indígenas, que llegan hablando dialecto y pensando en dialecto y a veces ni en dialecto." Recordemos -agregó el señor Acosta Corella- que en dialecto no hay artículo, número ni género; hay escasas palabras de relación y además ellos tienen construcciones diferentes." (Ministerio de Educación Pública, 1953, p.359).

\section{Referencias bibliográficas}

Aguirre, D. y Reinoso, A. (2006). El Amazonas colombiano. Pluralidad étnica y lingüística. En: Vacheron, F. y Betancourt, G. (Coords.), Lenguas y tradiciones orales de la Amazonía. 
¿Diversidad en peligro? (pp. 123179). La Habana: Fondo Editorial Casa de las Américas.

Bader, G. E. y Rossi C. A. (2002). Focus Groups. A Step-by-Step Guide [Grupos focales. Una guía paso a paso]. Canadá: The Bader Group.

Ballestero, R. (1952). Mi vida entre los guatusos. El maestro I, (8-9), 153-157.

Bozzoli de Wille, M. (1969). Localidades indigenas costarricenses. San José: EDUCA.

Castillo Vásquez, R. (2004). An Ethnogeography of the Maleku Indigenous Peoples in Northern Costa Rica [Etnogeografía de los indígenas malecus del norte de Costa Rica]. Tesis doctoral: University of Kansas.

Constenla Umaña, A. (1988). El guatuso de Palenque Margarita: su proceso de declinación. Estudios de Lingüistica Chibcha, 7, 7-37.

Constenla Umaña, A. (1998). Gramática de la lengua guatusa. Heredia: Editorial de la Universidad Nacional.

Crystal, D. (2001). La muerte de las lenguas. Cambridge: Cambridge University Press.

Garzon, S., Brown, R., Richards, J. y Ajpub', W. (1998). The Life of Our Language. Kaqchiquel Maya Maintenance, Shift, and Revitalization [La vida de nuestra lengua. Mantenimiento, cambio y revitalización del maya kaqchiquel]. Austin: The University of Texas Press.

Hagège, C. (2002). No a la muerte de las lenguas. Barcelona: Paidós.

House, D. (2005). Language Shift among the Navajos. Identity Politics and Cultural Continuity [Cambio de lengua entre los navajos. Política identitaria y continuidad cultural].Tucson: The University of Arizona Press.

Howard, R. (2007). Por los linderos de la lengua: Ideologías lingüisticas en los Andes. Lima: Instituto Francés de Estudios Andinos/Instituto de
Estudios Peruanos/Fondo Editorial de la Pontificia Universidad Católica del Perú.

Krashen, S. D. (1981). Second Language Acquisition and Second Language Learning [Adquisición de segundas lenguas y aprendizaje de segundas lenguas]. Oxford: Pergamon Institute of English.

Krueger, R. A. y Casey M. A. (2000). Focus Groups. A practical guide for applied research [Grupos focales. Una guía práctica para la investigación aplicada]. Londres: SAGE.

Lewis, M. P. (2001). K'iche'. A study in the Sociology of Language [K'iche'. Un estudio en el marco de la Sociología del Lenguaje]. Dallas: SIL International.

López, M. (1994). La situación del indio en Costa Rica: Un acercamiento a través de la opinión pública. Revista de Ciencias Sociales, 66,107-115.

Ministerio de Educación Pública. (1953). Actas de los cuatro Seminarios de las Escuelas Indígenas. El Maestro, 2(14), 355-360.

Morgan, D. L. (1997). Focus groups as qualitative research [Los grupos focales como investigación cualitativa]. Londres: SAGE.

Pachón, X. (1997). El nasa yuwe, o la lucha por la supervivencia de una lengua dominada. En: Pachón, X. y Correa, F. (Eds.), Lenguas amerindias. Condiciones sociolingüísticas en Colombia (pp. 269-319). Santafé de Bogotá: Instituto Caro y Cuervo.

Palacios, A. (2004). Factores que influyen en el mantenimiento, sustitución y extinción de las lenguas: Las lenguas amerindias. En: Lluís i Vidal-Folch, A. y Palacios, A. (Eds.), Lenguas vivas en América Latina (pp. 11-125). Madrid/ Barcelona: Universidad Autónoma de Madrid e Institut Català de Cooperación Iberoamericana.

Palmer, P., Sánchez J. y Mayorga, G. (1992). Vías de extinción. Vías de 
supervivencia. San José: Editorial de la Universidad de Costa Rica.

Pardo, M. (1997). Aspectos sociales de las lenguas chocó. En: Pachón, X. y Correa, F. (eds.), Lenguas amerindias. Condiciones sociolingüisticas en Colombia (pp. 321-381). Santafé de Bogotá: Instituto Caro y Cuervo.

Porras, A. (1959). El idioma guatuso: fonética y lexicología. Tesis de licenciatura: Universidad de Costa Rica.

Portilla, M. (1986). Un caso de muerte de lenguas: el térraba. Estudios de Lingüistica Chibcha, 5, 97- 246.

Quesada, M. A. (1995a). Revitalización de las lenguas indígenas de Costa Rica: el caso del boruca. En: Herranz, A., Barahona, M, Rivas, R. y Hamel, R. (Eds.), Educación bilingüe $e$ intercultural en Centroamérica y México (pp. 101-128). Tegucigalpa: Editorial Guaymuras.

Quesada, M. A. (1995b). Hablemos boruca (Chá din div tégat tegrá). San José: Ministerio de Educación Pública.

Quesada, M. A. (1999/2000). Situación actual y futuro de las lenguas indígenas de Costa Rica. Estudios de Lingüística Chibcha, 18-19, 7-34.

Quesada, M. A. (2008). América Central. En: Palacios, A. (Ed.), El español en América. Contactos lingüisticos en Hispanoamérica (pp. 57-75). Barcelona: Ariel.

Quesada, J. D. (2000). Synopsis of a Boruca terminal speaker [Sinopsis de un hablante terminal del boruca]. Amerindia, 25, 65-86.

Quesada, J. D. (2001/2002). Adiós boruca: Sibú ki ba wí?ra moréng. Estudios de Lingüistica Chibcha, 20-21, 55-64.

Ramírez, J., Jaén, M., Mejía, N. y Mojica, F. (1996). Historias malecu II. Vida y costumbres del indio malecu. Heredia: EUNA.

Rojas, C. (1997/1998). Revitalización lingüística de las lenguas indígenas de Costa Rica. Estudios de Lingüistica Chibcha, 16, 9-17.
Rojas, C. (2002). La enseñanza de las lenguas indígenas en Costa Rica. Educare, 3, 177-186.

Rojas, C. (2006). Actitudes hacia la enseñanza de las lenguas indígenas. Letras, 39, 267-271.

Russi, B. (1998). Grupos de discusión. De la investigación social a la investigación reflexiva. En: Galindo, J. (Coord.), Técnicas de investigación en sociedad, cultura y comunicación (pp. 75-115). México: Prentice Hall.

Sachdev, I. y Hanlon D. (2000/2001). Language attitudes, perceptions and identity: Some Haida and Cree data [Actitudes lingüísticas, percepciones e identidad: algunos datos del haida $\mathrm{y}$ del cree]. The London Journal of Canadian Studies, 16, 67-83.

Sánchez, C. (2011). El desplazamiento de la lengua guatusa en contacto con el español: Identidad étnica, ideologías lingüísticas y perspectivas de conservación. Tesis doctoral: Universidad Autónoma de Madrid.

Skutnabb-Kangas, T. (2000). Linguistic Genocide in Education- or worldwide diversity and human rights? [¿Genocidio lingüístico en la educación o diversidad y derechos humanos?]. Nueva Jersey: Lawrence Erlbaum Associates.

Tsunoda, T. (2005). Language Endangerment and Language Revitalization [Lenguas en peligro y revitalización lingüística]. Berlín: Mouton de Gruyter.

Ugalde, P. (1973). Guatuso. Un aporte a su estudio geo-económico y humano. Tesis de licenciatura: Universidad de Costa Rica.

van Dijk, T. (2000). Ideología. Una aproximación multidisciplinaria. Barcelona: Gedisa.

Vásquez, A. (2008). Caracterización de la situación idiomática de los pueblos indígenas de Costa Rica y su influencia en su educación. Revista Educare, 12 (número extraordinario), 61-66. 
Verkuyten, M.(2006). The Social Psychology of Ethnic Identity [Psicología social de la identidad étnica]. Nueva York: Routledge.
Wilson, J. (1996). Mitos del lenguaje. Expertos y autoridades. San José: Editorial de la Universidad de Costa Rica. 